\title{
Processing Characterization of Sisal/Epoxy Prepregs
}

\author{
Sayra O. Silva ${ }^{1}$, Linconl A. Teixeira ${ }^{1}$, Alexandre Bahia Gontijo ${ }^{2}$ and Sandra M. Luz ${ }^{1{ }^{*}}$ \\ ${ }^{1}$ Mechanical Sciences Graduate Program, University of Brasilia, Brasilia, Brazil \\ ${ }^{2}$ Forest Products Laboratory, Brazilian Forest Service, Brasília, Brazil
}

\begin{abstract}
Quality control to obtain composite laminates is frequently applied to synthetic fibers/epoxy prepregs. The gel time test, resin, volatiles and fiber content, drape measurement and tack tests together with water absorption capacity are methods currently employed. However, for natural fibers prepregs there is a gap in the literature, which makes their application difficult. Thus this work will investigate sisal fibers, which have low cost, high biodegradability and low specific weight, following the common methods to manufacture composites from natural fibers/epoxy prepregs. First, the prepregs were prepared by hand lay-up, aligning the fibers with epoxy, keeping $15 \%$ by weight content of fiber. After the quality control characterization, $3 \mathrm{~mm}$ thickness composite was prepared by using a press, and tensile tests and scanning electron microscopy (SEM) were applied. As a result, the resin fraction values and the solid content of the matrix showed little variation between the different samples. The natural fibers prepregs absorbed water quickly in the initial stage until reaching the saturation level. The $\mathrm{NaOH}$-treated sisal/epoxy prepreg had a tension of $71.06 \pm 8.28 \mathrm{kPa}$ for the tack test and tensile strength of $69.24 \pm 11.69 \mathrm{MPa}$. Finally, the $\mathrm{NaOH}$-treated sisal $15 \mathrm{wt} \% / \mathrm{epoxy}$ resulted in composites with a better performance than the neat epoxy resin. There was good adhesion between the fibers and matrix, as confirmed by SEM and mechanical tests.
\end{abstract}

Keywords: Natural fibers prepregs, sisal, gel time, resin, fibers and volatiles content, tack test, drape measurement.

\section{INTRODUCTION}

Although in the literature there are several studies on epoxy prepregs, little has been developed regarding natural fibers prepregs, especially with sisal fibers. The quality control of these materials is extremely necessary, as natural fibers have the capacity to replace or complement synthetic fibers to manufacture high-quality composites [1].

In general, the prepreg is an intermediate material ready for molding, although it is formed by a set of reinforcement fibers and thermosetting polymeric matrix, and is partially cross-linked [2]. Due to its low specific weight and high strength and stiffness values, this class of materials can replace some traditional metallic materials. Currently, the most common method of obtaining composites in the industry is through prepregs in the form of a tape or fabric, which is molded and cured without adding new products or resins [3].

The resin, fibers and volatile content, gel time, adhesion and water potential uptake are the main factors that guarantee the quality of a prepreg. Traditional analytical methods such as solvent extraction, weighing and combustion are often used to

*Address correspondence to this author at the Mechanical Sciences Graduate Program, University of Brasília, Brasília, Brazil; Tel: +55 61 982055197;

E-mail: sandraluz@unb.br measure the resin, fiber and volatiles content of the prepreg [4]. When the prepreg has a low amount of volatile substances, its aging is induced. The right quantities of resin and fibers in the prepregs provide the right degree of flexibility and the ideal handling capacity during the layer stacking process in the manufacture of laminated composites $[1,5]$. Thus, quantifying these values is extremely important in the process of manufacturing prepregs, especially because the fiber and resin content is hard to achieve for natural fibers.

Some other methods are used by the industry to analyze the quality and performance of prepregs before their effective use. Among them, the gel time checks the reactivity of the system from the time between the liquid phase and the first appearance of the solid phase [6]. This allows the ideal curing time and temperature to be evaluated to determine the best conditions to manufacture the prepreg and the composites [7].

Other important factors are the adherence capacity (tack test). This method checks the capacity of the prepreg to adhere to surfaces and to itself during molding. The drapeability capacity test of prepregs is commonly verified with the placement of the material in curved molds $[8,9]$.

Due to the hydrophilic character of the fibers, the water absorption capacity within the prepregs must 
also be verified, since a high aqueous capacity means a low adhesion between the fibers and the resin [10]. Costa et al. [11] reported that moisture absorption reduces the mechanical properties of these materials. Especially regarding natural fibers, the process of moisture absorption can occur due to capillary action, involving the pores or channels present in the fibers.

Although the mechanical properties of natural fibers are lower than synthetic ones, their density $(\sim 1.4$ $\left.\mathrm{g} / \mathrm{cm}^{3}\right)$ is approximately half that of glass fiber, to which the price would be approximate when compared to carbon fiber, which has a density similar to natural fibers [12]. In this context, composites reinforced with sisal fibers stand out for having high impact resistance, and good tensile and bending properties [13]. Sisal (Agave sisalana) is an attractive natural fiber option due to its rapid growth in a wide range of climatic conditions, and sisal lignocellulosic fiber is light, nontoxic and has a high modulus and specific resistance, in addition to causing less damage by abrasion to equipment and molds than inorganic fibers [14].

Therefore, sisal/epoxy prepregs are of considerable commercial interest. According to Webo et al. [15], the automotive industry is already considering the use of natural fibers, which would help not only in providing data for the industrial sector but also in the discovery of new materials that can be used in the future, since they are abundantly available. Besides that, the crop culture can promote opportunities to improve the living standards of people in a region [16].

Several studies have reported the use of synthetic fibers as a reinforcement for matrix polymers in particular prepregs; however, few have discussed the potential use of sisal fiber as a reinforcement of prepregs and how the quality of the processing of these materials interferes with the potential use by industries in general. Thus, this work aims to gain a better understanding of the sisal/epoxy prepreg behavior regarding the resin, fiber and volatile content, the adhering properties before curing such as tack and drapeability capacity, and the potential water uptake in order to optimize the processing to obtain natural fibers composites with considerable mechanical performance.

\section{MATERIALS AND METHODS}

\subsection{Materials}

Sisal fibers were supplied by (SisalSul Comércio e Indústria Ltda), from Sisaleira region Bahia, Brazil. Before treatment, the sisal fibers were cut to $25 \mathrm{~cm}$ length. Regarding the matrix, the AR 260 epoxy resin and $\mathrm{AH} 260$ hardener were supplied by E-composites, both from DML Chemicals in Brazil.

\subsection{Sisal Fibers Treatment}

The fibers were mercerized with a sodium hydroxide ( $97 \%$ pure; Greentec) solution at a concentration of $5 \%$ $(w / v)$. For that, they were immersed in a $\mathrm{NaOH}$ solution with a ratio of 10:1 (solution:fiber) in a water bath at 80 ${ }^{\circ} \mathrm{C}$ for $2 \mathrm{~h}$ under constant stirring. After the treatment, the fibers were washed with distilled water until neutral $\mathrm{pH}$. Finally, the filtered fibers were placed on a polypropylene tray at room temperature $\left(\sim 25{ }^{\circ} \mathrm{C}\right)$ for $96 \mathrm{~h}$ [17] until completely dry.

\subsection{Prepregs Fabrication}

The epoxy prepregs were obtained by the hand layup method (Figure 1), containing $15 \mathrm{wt} \%$ of fibers. First, the fibers were dried in an air-circulating oven (F2-DM, Fornitec, Brazil). Then, they were placed unidirectionally in a mold of $200 \mathrm{~mm}$ length (Figure 1A). The polymeric material was prepared by mixing the epoxy resin with a hardener at a ratio of 100:21 according to the manufacturer's instructions. Next, the resin mixture was applied to the fibers (Figure 1B).

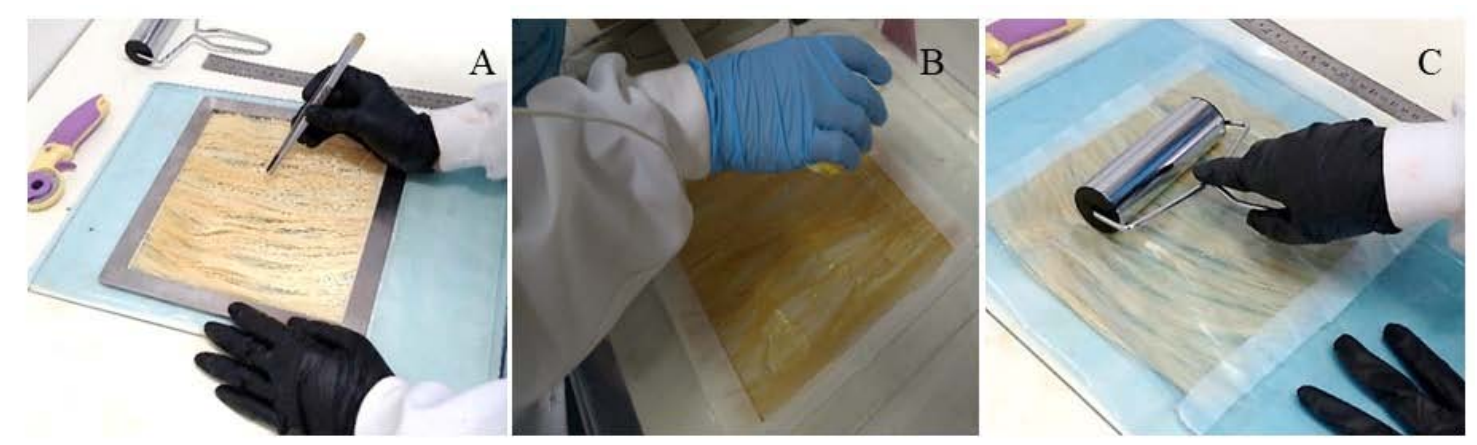

Figure 1: (A) The fiber is placed into the mold; (B) the fiber is wetted with epoxy resin and (C) the resin is spread over the fibers. 
Further, the resin was homogeneously spread with a metallic roller (Figure 1C). The prepreg was kept at room temperature until it reached stage $B$, followed by refrigeration $\left(-18^{\circ} \mathrm{C}\right)$.

\subsection{Prepregs Characterization}

\subsubsection{Gel Time, Differential Scanning Calorimetry (DSC) and Water Percentage Uptake}

The gel time was based on the American Society for Testing and Materials Standard (ASTM), ASTM D3532. The temperatures used to observe the gel time of the resin were determined from the DSC curve data, where three points of interest were chosen. Samples of the prepregs were placed on a glass slide previously heated for $20 \mathrm{~s}$ on a heating plate $(752 \mathrm{~A}$, Fisaton, Brazil) and probed until the resin did not show any flow. The time between the point at which the temperature was applied and the gel stage was recorded as the gel time. The experiments were performed in triplicate for each temperature.

For the DSC measurement, prepreg samples weighing $10 \pm 0.5 \mathrm{mg}$ were deposited on an alumina pan and covered with an alumina lid. The samples were analyzed in a simultaneous (TGA-DSC) thermal analyzer (Q600 SDT, TA Instruments, USA) under a nitrogen atmosphere with a gas flow of $50 \mathrm{~mL} \cdot \mathrm{mm}^{-1}$ at a heating rate of $2.5^{\circ} \mathrm{C} \cdot \mathrm{min}^{-1}$, from 25 to $300^{\circ} \mathrm{C}$.

The water percentage uptake was based on the method of Bhardwaj et al. [18], where six samples with dimensions of $100 \times 100 \mathrm{~mm}$ were weighed and their values were recorded as $\mathrm{G} 1$. Then, the samples were immersed in water for $5 \mathrm{~min}$ at $25^{\circ} \mathrm{C}$. After this time, the excess water was removed with absorbent paper and the weights were recorded as G2. The average of the weights for the six samples was used to obtain the percentage of water absorption with the following Equation (1), where the WPU is the water percentage uptake:

$W P U(\%)=\left(\frac{G 2-G 1}{G 1}\right) \times 100$

\subsubsection{Resin, Fiber and Volatile Content}

The resin content $(\mathrm{R} \%)$, fiber content $(\mathrm{FC} \%)$ and volatile content $(\mathrm{V} \%)$ were measured according to the ASTM D3529 and ASTM D3530 standards. Two samples $(50 \times 50 \mathrm{~mm})$ denoted as $A$ and $B$ were weighed separately, and their values were recorded as GA and GB. Then, the sample A was dissolved in 100 $\mathrm{mL}$ of acetone for 3 min under constant stirring and the excess material was filtered in a Buchner funnel previously weighed (GA1). After the filtration, the funnel was placed in an oven with air circulation at $160^{\circ} \mathrm{C}$ for $15 \mathrm{~min}$ to dry the sample completely. After the drying, its weight was recorded as GA2. The previously weighed sample $B$ was also placed in the oven with air circulation at $160{ }^{\circ} \mathrm{C}$ for $10 \mathrm{~min}$ and immediately afterward in a desiccator. After cooling, the sample weight was registered as GB1. The required data was calculated using the following Equations (2-4):

$$
\begin{aligned}
& R(\%)=\left(\frac{G A-(G 2-G 1)}{G A}\right) \times 100 \\
& V(\%)=\left(\frac{G B-G B 1}{G B}\right) \times 100 \\
& F C(\%)=\left(\frac{G A 2-G A 1}{G A}\right) \times 100
\end{aligned}
$$

\subsubsection{Drapeability Capacity}

The method developed by Shin et al. [19] was used for prepregs samples. Three sisal/ epoxy prepregs layers were placed at a $75^{\circ}$ angle, two with the partially polymerized resin/ hardener set (D-1 and D-2) and one with the fully polymerized set (F-1). D-1 was placed on the mold shortly after being manufactured, while D-2 after an interval of $1 \mathrm{~h}$ after five days of refrigeration. In addition, five layers of the material (D-2) were superimposed and placed in a mold, in order to see if the 'book effect' described by Lengsfiel et al. [20] occurred, where it is successful if no voids form inside the laminates. The objective was to compare the drapeability behavior at room temperature of the partially cured and fully cured samples and the ability to form molds with overlapping layers. The material was observed under a magnifying glass.

\subsubsection{Tack Test}

The tack test was carried out with the intention of investigating the tension necessary for the preimpregnated layers to separate. The test was performed based on the literature, as there are no standards that regulate this procedure. The test specimen was prepared with three prepregs layers of $100 \times 50 \times 1 \mathrm{~mm}$ (outer layers) and $50 \times 50 \times 1 \mathrm{~mm}$ (center layer). One side of the specimen was pressed with a load of $500 \mathrm{~N}$ for $30 \mathrm{~s}$ in a hydraulic press, forming a sandwich, while the larger sides were not pressed. The part not pressed was the region that would be trapped in the claws of the testing equipment. The experiments were performed in triplicate on a 
universal testing machine (Instron 8801, Instron, USA) equipped with a $100 \mathrm{kN}$ load cell at a speed of 2.5 $\mathrm{mm} \cdot \mathrm{min}^{-1}$.

\subsection{Composite Characterization}

\subsubsection{Composite Manufacturing by Using the Prepregs}

The composites plates with dimensions of $220 \times$ $200 \times 3 \mathrm{~mm}$ were prepared using 3 layers of prepregs. The not fully cured prepregs were molded using the dry lamination technique, which consists of stacking the pre-impregnated layers in a metallic mold. The $\mathrm{mold} / \mathrm{prepreg}$ set was inserted in a hydraulic press (P15T, Ribeiro, Brazil) under a load of $4.9 \mathrm{kN}$ at room temperature $\left(25^{\circ} \mathrm{C}\right)$ for $1 \mathrm{~h}$. The total cure followed at room temperature for $24 \mathrm{~h}$. Finally, post-curing was carried out in an oven at $60^{\circ} \mathrm{C}$ for $12 \mathrm{~h}$, as indicated by the manufacturer.

\subsubsection{Tensile Mechanical Test}

The tensile test was performed by ASTM D3039-14. The test specimen size was $200 \times 25 \times 2.5 \mathrm{~mm}$. The test was performed on a universal testing machine (Instron 8801, Instron, USA) equipped with a $100 \mathrm{kN}$ load cell at a speed of $1 \mathrm{~mm} \cdot \mathrm{min}^{-1}$. Five $(n=5)$ specimens of each composite were characterized for each type.

\subsubsection{Scanning Electron Microscopy (SEM)}

The surface morphology fractured surface of the composites was investigated by SEM (TM-4000Plus, Hitachi, Japan). There was no covering of the samples. The images were then captured using a voltage of 15 $\mathrm{kV}$ and $40 \times$ and $150 \times$ magnification.

\section{RESULTS AND DISCUSSION}

\subsection{Gel Time, Water Absorption and Volatiles Content of the Prepregs}

The gel time is the stage during the thermoset curing reaction, which can be classified as the transition from a liquid to a solid-state. The gel point occurs when the polymer begins to exhibit pseudoelastic properties. During the matrix processing, gelling should be avoided before the final shape is molded, since the material cannot be re-molded $[21,22]$.

According to the DSC curve (Figure 2A), three temperatures of interest were selected in the material's gelation region: 50,80 and $100{ }^{\circ} \mathrm{C}$. The average values for each temperature are plotted in Figure 2B, where it is possible to observe that the higher the temperature, the faster the gelation process takes place. The gradual increase in the viscosity that was observed at the beginning of the DSC curve could be due to a slow restructuring of the material system [23]. However, simply observing the evolution of the viscosity, it is not possible to determine the gel time accurately. Previous studies state that the heating rate of $2.5^{\circ} \mathrm{C} \cdot \mathrm{min}^{-1}$ is the most suitable for curing prepregs as this helps to control the curing of the system, and at temperatures below $100{ }^{\circ} \mathrm{C}$. Curing in an autoclave is unfeasible $[9,23]$, so the temperature of $100{ }^{\circ} \mathrm{C}$ is the most suitable for the consolidation process of the composites using the current resin (AR 260), since this temperature allows more controlled curing and prevents the formation of voids.
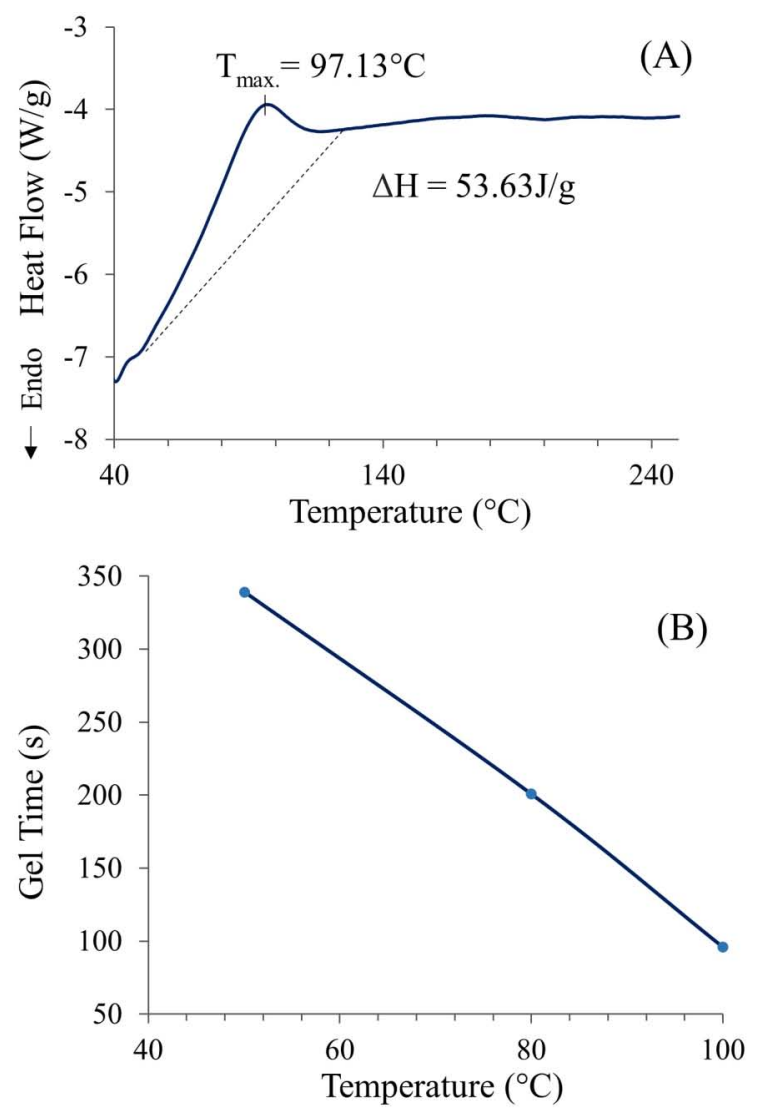

Figure 2: DSC curve (A) and gel time versus temperature (B).

According to Oh et al. [24] reported in their study regarding gel time for epoxy composites, the temperature of $80{ }^{\circ} \mathrm{C}$ was the longest, which contributes to a more efficient curing process.

The water percentage uptake is the ratio between the weight of the water absorbed by a material and the 
weight of its respective dry material. This test can only be performed during the prepreg manufacturing process, before freezing, because the storage and handling affect the measurement results $[21,25]$.

Table 1 shows the average water percentage uptake for the resin and prepregs after immersion in water at $2 \mathrm{~h}$ and $24 \mathrm{~h}$. According to Sreekumar et al. [10], the fibers absorb water quickly in the initial stage until the saturation level is reached, after which no further increase is obtained. This can be confirmed by the behavior of the sample, since, when the absorption reaches equilibrium, the weight gain for the untreated sisal/epoxy prepreg was $15.37 \%$ compared to the starting weight. The partially cured resin absorbed hardly any water, which can be explained by the hydrophobic character of the material.

As shown in Table 1, for the $\mathrm{NaOH}$-treated sisal/epoxy, the WPU value was approximately $10.78 \%$ at $24 \mathrm{~h}$ and increased over time, to around $14.31 \%$ compared to the weight of the sample after 2 hours immersed in water. According to the study by Abdelmola et al. [26], the saturation increases as the void content increases, so when the void volume is filled, the water absorption by the composite is equalized.

The WPU values showed that the $\mathrm{NaOH}$-treated sisal/epoxy prepregs had positive results when compared to untreated fibers/epoxy prepregs. In addition to obtaining a more homogeneous material, the few voids and the better wettability make it difficult for moisture to enter due to the good adhesion between the reinforcement and the matrix. Sreekumar et al. [10] also reported that mercerized sisal fiber reinforcing materials had a lower water absorption rate.

The initial weight content for the resin adopted for the production of prepregs was $85 \mathrm{wt} \%$. However, during the processing, some experimental issues such as weight losses, volatiles and the natural fibers humidity content can change the resin and fibers content. The measurement of the fiber/resin fraction was determined from the size of the mold and the density of the resin as indicated by the manufacturer $\left(1.15{\mathrm{~g} . \mathrm{cm}^{-3}}^{-3}\right.$, as we described in the method part of this paper. As shown in Table 1, the real resin content in the prepregs was $82.78 \mathrm{wt} \%$, and the fiber content was $17.22 \mathrm{wt} \%$. Considering the resin content and the solid content of the matrix, they presented little variation between the different samples. It is possible to infer that the existing difference was influenced by the volatiles content present in the resin or voids contained in the material.

The volatile content obtained from the aforementioned standard showed an average of 1.64 wt\%, which follows the acceptable values [5]. Moreover, Xia et al. [27] observed that the lower the volatile content, the higher the rate of use of the system, since the number of voids contained within the material is reduced, which causes an increase in properties in composites. The prepreg in question had five days of freezer cooling, and although this study does not consider the storage time, it is possible that some of the volatile loss occurred during this time, since the storage time influences the volatile content in the material [28].

\subsection{Drapeability and Tack Test for the Prepregs}

Figure 3 shows the drapeability capacity with a $75^{\circ}$ angle to simulate the shape of a corner mold. The partially cured samples proved to be flexible and easily cut, whereas the cured sample had reduced flexibility and increased rigidity, as can be seen in Figure $\mathbf{3 A}$, thus losing the ability to adhere to other layers, making it impossible to mold under these conditions. Shin et al. [19] reported a similar behavior in their work with thermoplastic resin, differentiated only due to the possibility of heating, which restored the material's

Table 1: Water Percentage Uptake (WPU) and Content Data for the Resin and Prepregs

\begin{tabular}{|c|c|c|c|}
\hline Specimen/ Properties & Partially cured resin & Untreated sisal 15 wt\%/ epoxy & $\begin{array}{c}\text { NaOH-treated sisal 15 wt\%l } \\
\text { epoxy }\end{array}$ \\
\hline \hline WPU after 2 h (\%) & $0.68 \pm 0.17$ & $14.31 \pm 2.10$ & $9.43 \pm 3.37$ \\
\hline WPU after 24 h (\%) & $0.78 \pm 0.27$ & $16.51 \pm 3.73$ & $10.78 \pm 3.64$ \\
\hline Resin Content (wt\%) & - & - & - \\
\hline Volatile Content (wt\%) & - & - & $82.78 \pm 2.18$ \\
\hline Solid Matrix Content (wt\%) & - & - & $1.64 \pm 0.43$ \\
\hline Fiber Content (wt\%) & - & & $17.22 \pm 2.61$ \\
\hline
\end{tabular}




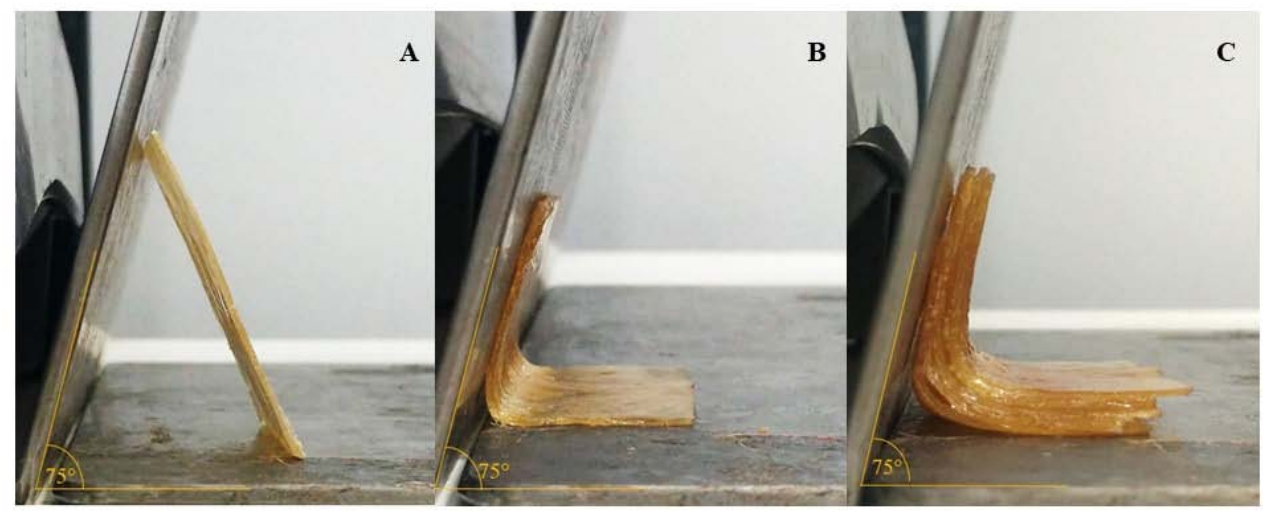

Figure 3: $\mathrm{NaOH}$-treated sisal/epoxy fully cured prepreg $(\mathbf{A})$, one layer of partially cured prepreg (B) and five layers of partially cured prepregs $(\mathbf{C})$.

ability to adhere and mold, which is not possible with thermoset resins.

$\mathrm{NaOH}$-treated sisal/epoxy prepregs were placed at the corner, one layer shown in Figure $3 \mathrm{~B}$ and five layers in Figure $\mathbf{3 C}$. We can see in both cases that there is adhesion on the plate, most effectively for one layer. In the case of the three-layer sample, they did not adhere effectively to the corner of the mold. However, the prepregs layers completely adhered to each other without leaving voids (Figure 3C). In composites, the stiffness and strength are determined by the reinforcing fibers, so it is essential to maintain the initial and precise positioning of the fibers throughout the manufacturing process according to Wang et al. [29], as inefficient handling can cause the spreading/distortion of the fibers and the reduction of volume in certain places since even the partially polymerized the matrix tends to flow.

Figure 4 shows a typical tack test for the prepregs pulled through the two claws of the tensile clamps to simulate the separation of the surface from the laminated layers. During the dismemberment, the fibers move from the resin, while fibrillation begins. Although the adhesion of the prepregs cannot be quantified exactly, it was possible to observe the average values of maximum stress during the separation of the laminates. The $\mathrm{NaOH}$-treated sisal $15 \mathrm{wt} \% / \mathrm{epoxy}$ prepreg presented a tension of $71.06 \pm 8.28 \mathrm{kPa}$. No maximum stress values were found in the literature, only the separation energy for glass/epoxy and glass/phenolic prepregs $[9,30]$.

It was observed that the $\mathrm{NaOH}$-treated sisal/epoxy prepreg showed a high adherence capacity, since the material is capable of adhering to itself and to surfaces. According to Silva et al. [28], this material is qualified as Level $\mathrm{V}$ (high adhesion, glue on gloves, adheres to itself and other surface). As it is a complex phenomenon, it is not possible to decompose the adhesion properties into a single value. Therefore, a whole set of tests must be taken into consideration. Recently, two test methods are being developed by the ASTM Committee: ASTM WK67852 and WK70428 [31]. Thus, this study aims to only inform of the behavior of prepregs at the time when two previously pressed layers separate.

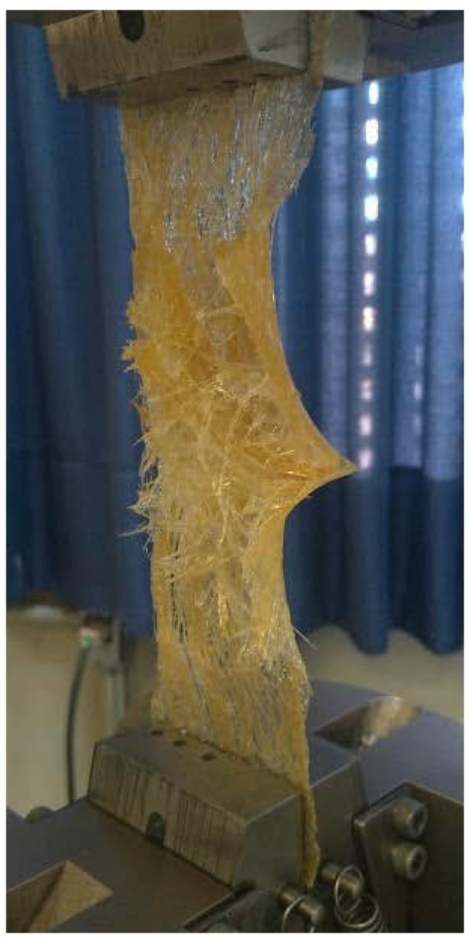

Figure 4: Separation of the laminated layers during tack test, $\mathrm{NaOH}$-treated sisal epoxy prepreg.

\subsection{Tensile Behavior and Morphology of Fracture of the Composites}

Figure 5 shows the stress-strain curves for the $\mathrm{NaOH}$-treated sisal/epoxy composites built with five 
layers of pressed prepregs, compared to the neat matrix. It is clear that the elongation at break for the samples is low, due to the characteristic fragile behavior in thermoset matrices.

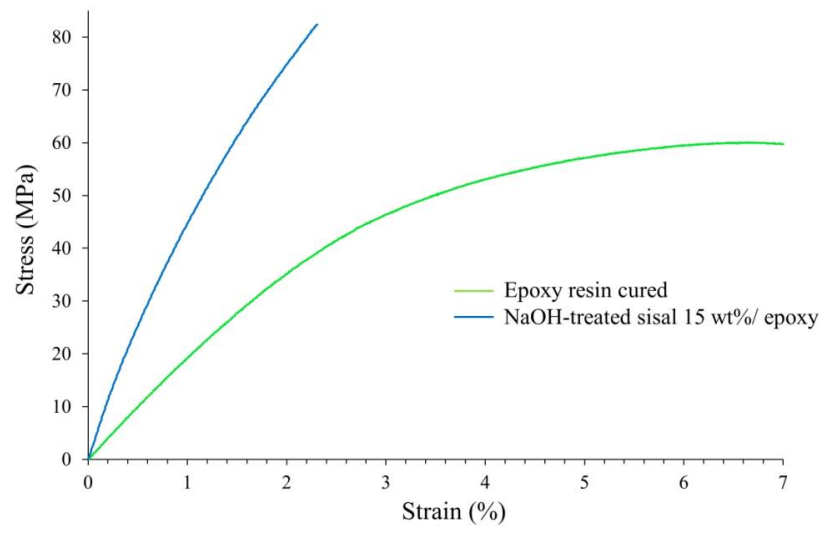

Figure 5: Stress-strain curves for epoxy resin and the sisal/epoxy composites.

According to the data presented in Table 2, there was an increase in the mean values of tensile strength for $\mathrm{NaOH}$-treated sisal composites to higher than the neat epoxy resin. Thus, there was a $28 \%$ increase in the tensile strength compared to the neat matrix. The good tensile properties for the sisal fiber composites can be explained by the aligning of the fiber within the composite. Vimalanathan et al. [32] concluded that fiber orientation and adhesion are directly linked to the tensile properties of a composite. In addition, the fibers must comply with the length of the load direction so that the tensile strength of the composites can be applied effectively.

According to Table 2, the sisal/epoxy composites showed higher Young's modulus values $(3.33 \pm 0.26$ $\mathrm{GPa}$ ) than the epoxy resin. A study using polyester composites and sisal fibers treated with $\mathrm{NaOH}$ also showed higher Young's modulus values $(3.02 \pm 0.05$ $\mathrm{GPa}$ ) when compared to other treatments [10]. However, the addition of the fibers reduced the elongation capacity of the material [33].

Surface images of the $\mathrm{NaOH}$-treated sisal 15 wt\%/epoxy composites are shown in Figure 6. Figure 6A shows a number of fibers pulled from the matrix, a failure mechanism known as pull-out, which is commonly found in composites reinforced with unidirectional fibers [33]. An increase in the image size (Figure 6B) shows that there was no fiber defibrillation during extraction, a behavior similar to that reported by Ma et al. [34].

In addition, it is observed (Figure 6A) that there was a good adhesion between fiber/ matrix, which contributed to greater tensile strength. The same behavior was reported by Teixeira et al. [33] in polyester resin composites reinforced with curaua fibers. Moreover, according to Sankar et al. [35] this better fiber/ matrix interface contributes to a more

Table 2: Tensile Properties for the NaOH-Treated Sisal/ Epoxy Composites

\begin{tabular}{|c|c|c|}
\hline Properties/ materials & Epoxy resin fully cured & NaOH-treated sisal 15 wt\%/ epoxy \\
\hline \hline Tensile strength (MPa) & $53.7 \pm 7.25$ & $69.24 \pm 11.69$ \\
\hline Elongation at break (\%) & $5.32 \pm 1.82$ & $2.07 \pm 0.23$ \\
\hline Young's modulus (GPa) & $1.09 \pm 0.30$ & $3.33 \pm 0.26$ \\
\hline
\end{tabular}

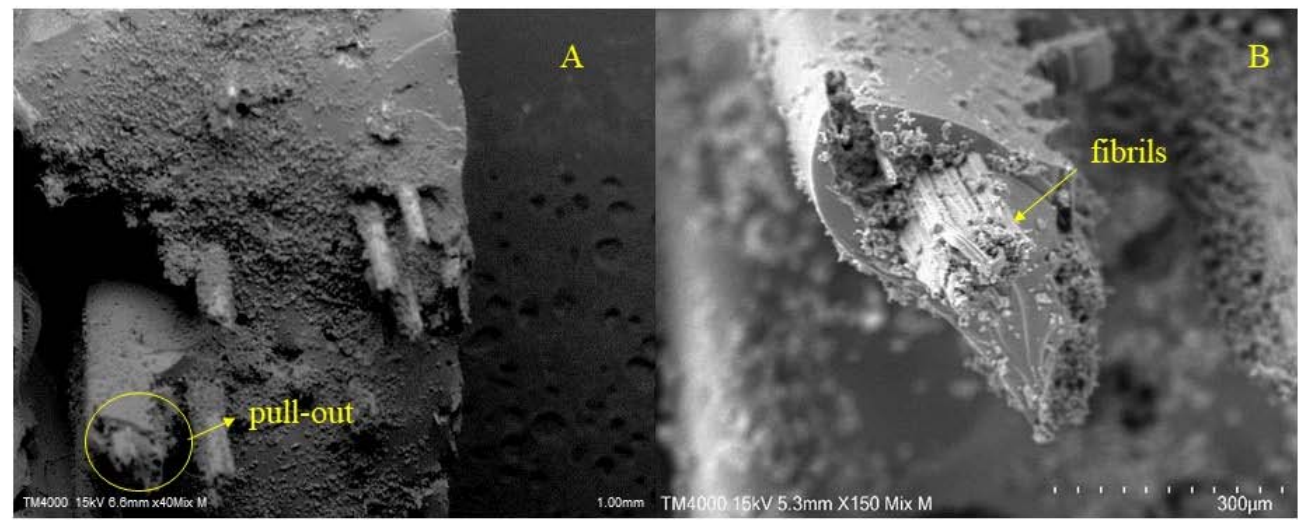

Figure 6: SEM images (40x and 150x magnification) of $\mathrm{NaOH}$-treated sisal/epoxy composites. 
efficient load transfer. Thus, the fiber strongly bonded to the matrix imparts a high strength and stiffness to the composite.

The composites showed visible resin residues on the fibers. According to Yan et al. [36], this behavior is expected due to the previous treatment carried out on the fibers, which removes the layer of lignin and waxes and allows a better interfacial compatibility between the fiber and the matrix. These observations corroborate the results of the mechanical tests, since the perception of the fiber direction within the composite in the fracture region influences the material properties.

\section{CONCLUSIONS}

The main findings regarding the quality control for sisal fibers/ epoxy prepregs to obtain composite laminates were:

1. The gel time showed that as the temperature increases, the gel time decreases, due to a faster formation of the cross-link process;

2. There was a low proportion of volatile content for the prepregs developed in this study, and the resin and fibers content were as proposed;

3. The drapeability capacity showed that the adhesion on the mold is most effective for one prepreg layer, and the adhesion between the layers seems effective;

4. The tack test obtained mean values of maximum stresses around $71.06 \pm 8.28 \mathrm{kPa}$;

5. The $\mathrm{NaOH}$-treated sisal resulted in prepregs with lower water absorption than the untreated fibers; and

6. The tensile test showed that $\mathrm{NaOH}$-treated sisal $15 \mathrm{wt} \% /$ epoxy showed better tensile strength and Young's modulus results compared to the neat matrix.

To conclude, the commonly used methods to characterize the prepregs can be successfully applied to natural fibers prepregs, resulting in composites with superior tensile properties when compared to neat matrix.

\section{ACKNOWLEDGEMENTS}

The authors would like to thank CAPES (Coordenação de Aperfeiçoamento de Pessoal de
Nível Superior), DPG/UnB (Decanato de Pós Graduação/University of Brasília), FAPDF (Fundação de Apoio à Pesquisa do Distrito Federal) and CNPq (Conselho Nacional de Desenvolvimento Científico e Tecnológico) for the financial support for this project.

\section{REFERENCES}

[1] Ji KJ, Wei CY, Deng WH, Zhang YS, Liu YJ, Mao RZ, et al. Evaluation of Glass Fibre/Epoxy Prepreg Quality during Storage. Polym Polym Compos [Internet] 2002; 10(8): 599606.

https://doi.org/10.1177/096739110201000803

[2] Park H. Dielectric cure determination of a thermosetting epoxy composite prepreg. J Appl Polym Sci [Internet] 2017; 134(15): 1-9. https://doi.org/10.1002/app.44707

[3] Maria J, Paiva F De, Mayer S, Cerqueira M. Comparison of Tensile Strength of Different Carbon Fabric Reinforced Epoxy Composites 2006; 9(1): 83-9. https://doi.org/10.1590/S1516-14392006000100016

[4] Lo J, Anders M, Centea T, Nutt SR. The effect of process parameters on volatile release for a benzoxazine-epoxy RTM resin. Compos Part A Appl Sci Manuf 2016; 84: 326-35. https://doi.org/10.1016/j.compositesa.2016.01.024

[5] Jiang B, Huang YD, Li W, Liu L. Non-destructive and rapid analysis of resin and volatile contents in carbon fibre/epoxy resin prepreg cloth by near-infrared spectroscopy. Iran Polym J 2007; 16: 319-26.

[6] Shimkin AA. Methods for the determination of the gel time of polymer resins and prepregs. Russ J Gen Chem [Internet] 2016; 86(6): 1488-93. https://doi.org/10.1134/S107036321606044X

[7] Hayaty M, Beheshty MH, Esfandeh M. A new approach for determination of gel time of a glass/epoxy prepreg. J Appl Polym Sci [Internet] 2011; 120(3): 1483-9. https://doi.org/10.1002/app.33251

[8] Endruweit A, Choong GYH, Ghose S, Johnson BA, Younkin DR, Warrior NA, et al. Characterisation of tack for unidirectional prepreg tape employing a continuous applicationand-peel test method. Compos Part A Appl Sci Manuf [Internet] 2018; 114(May): 295-306. https://doi.org/10.1016/j.compositesa.2018.08.027

[9] Rajaei M, Beheshty MH, Hayaty M. Preparation and Processing Characterization of Glass/Phenolic Prepregs. Polym Polym Compos [Internet] 2011; 19(9): 789-96. https://doi.org/10.1177/096739111101900909

[10] Sreekumar PA, Thomas SP, Saiter J marc, Joseph K Unnikrishnan G, Thomas S. Effect of fiber surface modification on the mechanical and water absorption characteristics of sisal/polyester composites fabricated by resin transfer molding. Compos Part A Appl Sci Manuf [Internet] 2009; 40(11): 1777-84. https://doi.org/10.1016/j.compositesa.2009.08.013

[11] Costa ML, Rezende MC, de Almeida SFM. Effect of Void Content on the Moisture Absorption in Polymeric Composites. Polym Plast Technol Eng [Internet] 2006; 45(6): 691-8.

https://doi.org/10.1080/03602550600609549

[12] Faruk O, Bledzki AK, Fink HP, Sain M. Biocomposites reinforced with natural fibers: 2000-2010. Prog Polym Sci [Internet] 2012; 37(11): 1552-96. https://doi.org/10.1016/j.progpolymsci.2012.04.003

[13] Lalit R, Mayank P, Ankur K. Natural fibers and biopolymers characterization: A future potential composite material. Stroj Cas 2018; 68(1): 33-50. https://doi.org/10.2478/scjme-2018-0004 
[14] Negawo TA, Polat $Y$, Buyuknalcaci FN, Kilic A, Saba N, Jawaid M. Mechanical, morphological, structural and dynamic mechanical properties of alkali treated Ensete stem fibers reinforced unsaturated polyester composites. Compos Struct [Internet] 2019; 207(10): 589-97. https://doi.org/10.1016/j.compstruct.2018.09.043

[15] Webo W, Masu L, Maringa M. The Impact Toughness and Hardness of Treated and Untreated Sisal Fibre-Epoxy Resin Composites. Adv Mater Sci Eng 2018. https://doi.org/10.1155/2018/8234106

[16] Satyanarayana KG, Wypych F, Guimarães JL, Amico SC, Sydenstricker THD, Ramos LP. Studies on Natural Fibers of Brazil and Green Composites. Metals Materials and Processes 2005.

[17] Spinacé MAS, Lambert CS, Fermoselli KKG, De Paoli MA. Characterization of lignocellulosic curaua fibres. Carbohydr Polym [Internet] 2009; 77(1): 47-53. https://doi.org/10.1016/j.carbpol.2008.12.005

[18] Bhardwaj A, Patel K, Bhardwaj MC, Fetfatsidis KA. High accuracy measurement of prepreg level of impregnation using non-contact ultrasound. In: Composites and Advanced Materials Expo 2015.

[19] Shin JH, Kim D, Centea T, Nutt SR. Thermoplastic prepreg with partially polymerized matrix: Material and process development for efficient part manufacturing. Compos Part A Appl Sci Manuf [Internet] 2019; 119(July 2018): 154-64. https://doi.org/10.1016/j.compositesa.2019.01.009

[20] Lengsfeld H, Wolff-Fabris F, Krämer J, Lacalle J, Altstädt V. Composite Technology. In: Lengsfeld $\mathrm{H}$, Wolff-Fabris $\mathrm{F}$, Krämer J, Lacalle J, Altstädt VBT-CT, editors. Composite Technology [Internet]. München: Carl Hanser Verlag $\mathrm{GmbH}$ \& Co. KG; 2015. p. I-XV. https://doi.org/10.3139/9781569906002.fm

[21] Harper CA, Petrie EM. Plastics Materials and Processes: A concise encyclopedia. A John Wiley \& Sons, Inc. New Jersey and Canada; 2003.

[22] Vidil T, Tournilhac F, Musso S, Robisson A, Leibler L. Control of reactions and network structures of epoxy thermosets. Prog Polym Sci 2016. https://doi.org/10.1016/j.progpolymsci.2016.06.003

[23] Costa ML, Rezende MC, Botelho EC. Estabelecimento de ciclo de cura de pré-impregnados aeronáuticos. Polímeros: Ciência e Tecnologia 2005. https://doi.org/10.1590/S0104-14282005000300014

[24] Oh D-H, Kim H-S, Shim J-H, Jeon Y-H, Kang D-W, Lee B-W. Characteristics of Gel Time and Dielectric Strength of Epoxy Composite According to the Mixing Ratio of Micro-Fillers. Energies [Internet] 2020; 13(19): 5165. https://doi.org/10.3390/en13195165

[25] Lengsfeld H, Wolff-Fabris F, Krämer J, Lacalle J, Altstädt V. Composite Technology: Prepregs and Monolithic Part Fabrication Technologies 2016. https://doi.org/10.3139/9781569906002.fm

[26] Abdelmola F, Carlsson LA. State of water in void-free and void-containing epoxy specimens. J Reinf Plast Compos 2019; 38(12): 556-66.

https://doi.org/10.1177/0731684419833469
[27] Xia Y, Zhou C, Liang G, Gu A, Wang W. Polyester-imide solventless impregnating resin and its nano-silica modified varnishes with excellent corona resistance and thermal stability. IEEE Trans Dielectr Electr Insul [Internet] 2015; 22(1): 372-9. https://doi.org/10.1109/TDEI.2014.004251

[28] Silva ACTN da, Guilherme F, Ferrari VM, Ferrari PE. Investigation of the effect of exposure time at room temperature in a structural epoxy resin adhesive film. Polímeros [Internet] 2016; 26(1): 92-100. Available from: http://www.scielo.br/scielo.php?script=sci_arttext\&pid=S0104 $-14282016000100013 \&$ Ing=pt\&tlng=pt

[29] Wang J, Paton R, Page JR. The draping of woven fabric preforms and prepregs for production of polymer composite components. Compos Part A Appl Sci Manuf [Internet] 1999; 30(6): 757-65. https://doi.org/10.1016/S1359-835X(98)00187-0

[30] Banks R, Mouritz AP, John S, Coman F, Paton R. Development of a new structural prepreg: characterisation of handling, drape and tack properties. Compos Struct [Internet] 2004; 66(1-4): 169-74 https://doi.org/10.1016/j.compstruct.2004.04.034

[31] Budelmann D, Schmidt C, Meiners D. Prepreg tack: A review of mechanisms, measurement, and manufacturing implication. Polym Compos 2020; 41(9): 3440-58. https://doi.org/10.1002/pc.25642

[32] Vimalanathan $P$, Venkateshwaran N, Santhanam V. Mechanical, dynamic mechanical, and thermal analysis of Shorea robusta-dispersed polyester composite. Int J Polym Anal Charact 2016; 21(4): 314-26. https://doi.org/10.1080/1023666X.2016.1155818

[33] Teixeira LA, Vilson Dalla Junior L, Luz SM. Chemical treatment of curaua fibres and its effect on the mechanical performance of fibre/polyester composites. Plast Rubber Compos [Internet] 2020; 1-11. https://doi.org/10.1080/14658011.2020.1862978

[34] Ma L, He LJ, Shao SY. Study on Effect of Surface Treating Method on Mechanical Behavior of Three Plant Fiber Reinforced Polypropylene Composites. Polym Polym Compos [Internet] 2017; 25(1): 93-102. https://doi.org/10.1177/096739111702500113

[35] Sankar PH, Reddy YVM, Reddy KH, Kumar MA, Ramesh A The Effect of Fiber Length on Tensile Properties of Polyester Resin Composites Reinforced by the Fibers of Sansevieria trifasciata. Int Lett Nat Sci [Internet] 2014; 8: 7-13. https://doi.org/10.18052/www.scipress.com/ILNS.8.7

[36] Yan L, Chouw N, Huang L, Kasal B. Effect of alkali treatment on microstructure and mechanical properties of coir fibres, coir fibre reinforced-polymer composites and reinforcedcementitious composites. Constr Build Mater [Internet] 2016; 112: $168-82$. https://doi.org/10.1016/j.conbuildmat.2016.02.182

(C) 2021 Silva et al.; Licensee Lifescience Global.

This is an open access article licensed under the terms of the Creative Commons Attribution Non-Commercial License (http://creativecommons.org/licenses/by-nc/3.0/) which permits unrestricted, non-commercial use, distribution and reproduction in any medium, provided the work is properly cited. 